Article

\title{
Rheological and Electrical Study of a Composite Material Based on an Epoxy Polymer Containing Cyclotriphosphazene
}

\author{
O. Dagdag 1,*(D, M. El Gouri ${ }^{1}$, A. El Mansouri ${ }^{2}$, A. Outzourhit ${ }^{3}$, A. El Harfi ${ }^{4}$, O. Cherkaoui ${ }^{5}$,
} A. El Bachiri ${ }^{6}$, O. Hamed ${ }^{7}$, S. Jodeh ${ }^{7, * \mathbb{D}}$, G. Hanbali ${ }^{7}$ and B. Khalaf ${ }^{7}$

1 Laboratory of Industrial Technologies and Services (LITS), Department of Process Engineering, Height School of Technology, Sidi Mohammed Ben Abdallah University, P.O. Box 2427, Fez 30000, Morocco; gouri_mustapha@yahoo.fr

2 LPSCM, Department of physics, Faculty of Sciences Semlalia, Cadi Ayyad University, Marrakech PB 2390, Morocco; a.elmansouri@ucam.ac.ma

3 Nanomaterials for Energy and Environment Laboratory, Cadi Ayyad University, Marrakech PB 2390, Morocco; aoutzour@ucam.ac.ma

4 Laboratory of Advanced Materials and Process Engineering, Department of Chemistry, Faculty of Science, Ibn Tofail University, BP 133, Kenitra 14000, Morocco; a.elharfi@outlook.fr

5 Higher School of Textile and Clothing Industries, Laboratory REMTEX, Oulfa BP 7731, Casablanca, Morocco; cherkaoui@esith.ac.ma

6 University Department, Royal Naval School, Sour Jdid Boulevard, Casablanca B.P 16303, Morocco; abderrahimelbachiri71@gmail.com

7 Department of Chemistry, An-Najah National University, Nablus P. O. Box 7, Palestine; ohamed@najah.edu (O.H.); g.hanbali@najah.edu (G.H.); bayan.kh107@hotmail.com (B.K.)

* Correspondence: omar.dagdag@uit.ac.ma (O.D.); sjodeh@hotmail.com (S.J.); Tel.: +33-06-01831572 (O.D.); +970-599590498 (S.J.)

Received: 29 February 2020; Accepted: 24 March 2020; Published: 16 April 2020 updates

\begin{abstract}
In this work, we have studied, formulated, prepared, and characterized the rheological and electrical behavior of a composite material based on an epoxy resin Diglycidyl Ether of Bisphenol A (DGEBA) reinforced with hexaglycidyl cyclotriphosphazene (HGCP). The epoxy system was cured with 4,4'-methylene dianiline (MDA). DGEBA-HGCP-MDA epoxy composite materials with reinforced HGCP which varied from $5 \%$ to $10 \%$ by weight were prepared by mixing in the molten state. The morphology was evaluated by SEM. The rheological behavior was studied using small deformation rheology. The electrical characterization was carried out with a frequency variation range from $1 \mathrm{~Hz}$ to $100 \mathrm{KHz}$ at room temperature. These measurements revealed that the rheological and electrical behaviors strongly depend on the quantity of HGCP in the DGEBA matrix. The linear viscoelastic properties study reveals that the modulus of elasticity $G^{\prime}$ is dependent on the amount of HGCP present in the epoxy resin DGEBA. The capacitance-frequency measurements suggest a distribution of localized states in the band gap of the blends.
\end{abstract}

Keywords: epoxy resin; HGCP; composite; rheological and electrical behavior

\section{Introduction}

Epoxy resins are thermosetting polymers that have been extensively employed in various areas such as aerospace, coatings, adhesives, electronic devices, laminates and encapsulations due to the characteristics of outstanding mechanical and electrical properties, relatively low curing shrinkage, superior adhesion to substrates as well as good thermal, chemical and corrosion resistance [1-8]. 
Hexachlorocyclotriphosphazene is a procured oligomer usually used for the synthesis of phosphazene-based polymers $[9,10]$. The groups like chlorine which are attached to the phosphorus atoms are usually treated as good leaving groups which are easily replaced by various nucleophiles to form cyclotriphosphazene reagents. incorporation of cyclotriphosphazene in a thermosetting polymer network could add several advantages to the polymer like for instance, it enhances the network thermal, mechanical and electrochemical properties. This could be attributed to the synergy of phosphorus and nitrogen [11-13]. However, they have poor compatibility with epoxy resin which leads to reduce mechanical properties of composites and limit their application. This problem might be solved by the technique of chemical modification. By grafting the organic group on cyclotriphosphazene, the compatibility is supported between the inorganic layer of cyclotriphosphazene and organic layer of the epoxy resin matrix. This technique is similar with that concerning the enveloping microscopic amounts of matter (solid particles, droplets of liquids, or gas bubbles) in a thin film of polymer which forms a solid wall [14,15]. This core/shell structure allows the isolation of the encapsulated substance from the immediate surroundings and thus protects it from any degrading factors such as temperature and improves the dispersion.

In this work the three epoxy components (DGEBA-HGCP MDA) was reinforced by various amount of hexaglycidyl of cyclotriphosphazene (HGCP). The amounts of HGCP ranged from $5 \%$ to $10 \%$. The epoxy system was cured with the MDA. Produced thermosetting network was characterized by various techniques that include morphology by SEM, rheology by HAAKE MARS Modular Advanced Rheometer System and electrical study by Keithley 3330LCZ impedance meter.

\section{Experimental}

\subsection{Materials and Methods}

The chemical structures of the materials studied in this work are represented in Figure 1. The material was diglycidyl ether of bisphenol A (DGEBA) type Epon 828, the curing agent $4,4^{\prime}$-methylene dianiline (MDA) and hexaglycidyl of cyclotriphosphazene (HGCP). The synthesis of HGCP resin was carried out according to a published procedure [16].

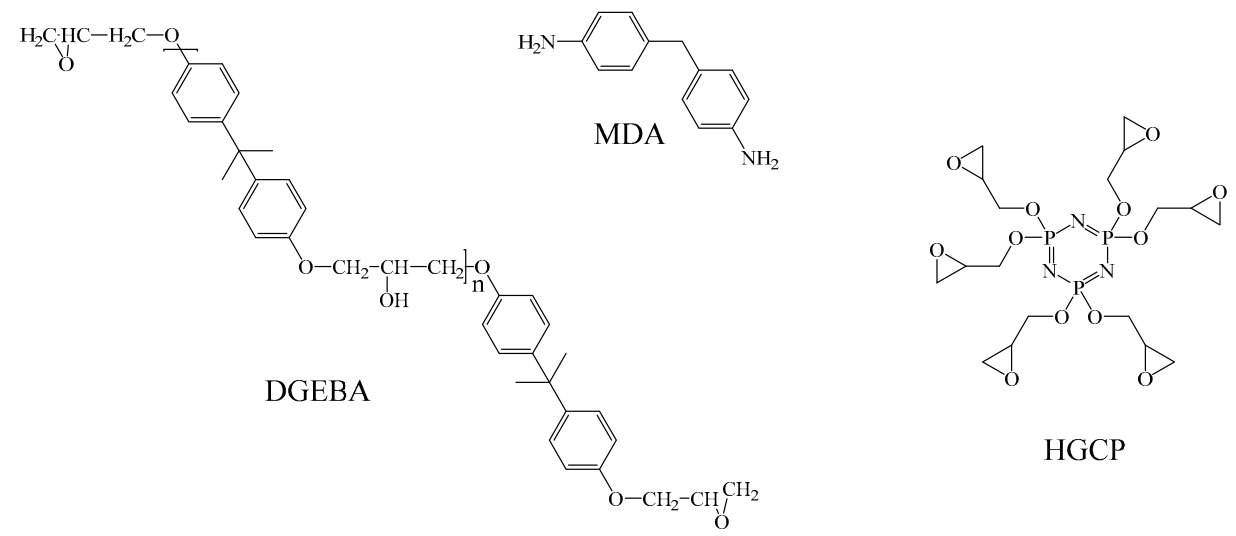

Figure 1. Chemical structures of the epoxy materials and the curing agent.

\subsection{Sample Preparation}

Mixing the polyepoxide and the hardener (curing agent) produced a bridged three-dimensional network as shown in Figure 2. The curing process was exothermic, the crosslinked materials were hard. They could therefore respond to use in a wide temperature range. The procedures of mixing epoxy resin with hardener before crosslinking was followed by Levin [17]. MDA was crystallized at room temperature, then placed in an oven at $120^{\circ} \mathrm{C}$ (more than melting point) and the resin was brought to $70^{\circ} \mathrm{C}$. After melting, the was mixed to form a single phase which was at $70{ }^{\circ} \mathrm{C}$. The samples thus prepared were sealed in Teflon molds and underwent the following cooking cycle: 
- $\quad$ One night at $70{ }^{\circ} \mathrm{C}$

- $\quad 3 \mathrm{~h}$ at $100^{\circ} \mathrm{C}$

- $2 \mathrm{~h}$ at $120^{\circ} \mathrm{C}$

- $1 \mathrm{~h}$ at $140^{\circ} \mathrm{C}$

- 30 min at $150^{\circ} \mathrm{C}$

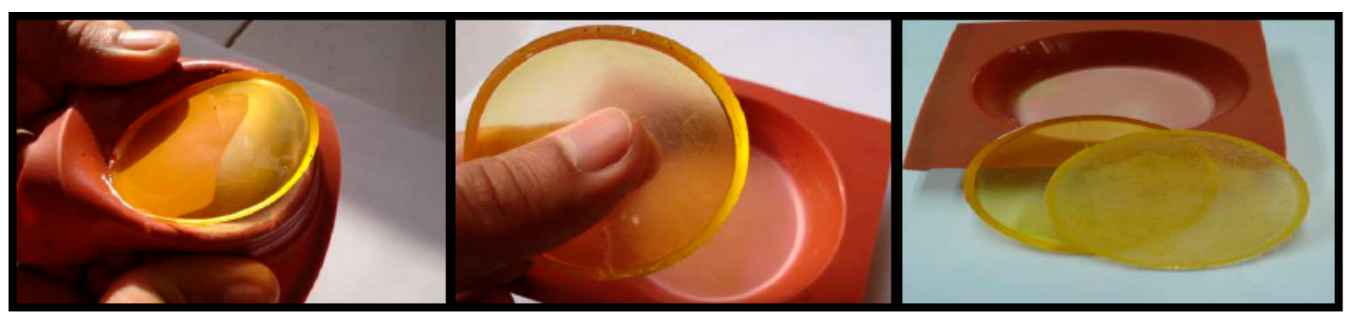

Figure 2. Sample preparation technique.

\subsection{HGCP Dispersion Approach in a Polymer Matrix}

Numerous studies have already demonstrated that the physical properties largely depend on the degree of dispersion of the nanoparticles in the polymer matrices. Mainly, the influence of the degree of dispersion on the rheological and mechanical properties is well known. The absence of chemical bonds and compatibility between the polymer and the particle, which has a link with the dispersion, can influence the mechanical properties of the composites because a strong interfacial bond can effectively transfer the load from the matrix to the reinforcement. Often used are the chemical surface modification of the inorganic nanoparticle, the modification of the deposition reaction, the chemical modification of mechanical force, the modification by high energy and the modification by polymer surface grafting and intercalation. These changes resolve the heterogeneous aggregation issues. The interactions between the reactive groups of the polymer and the nanoparticles depend on the chemical structure of the polymer and the surface charge of the nanoparticles. Good dispersion was expected due to the organic group on the HGCP and since DGEBA is epoxy resin. Due to the compatibility between two species, the flame retardant additive dispersed in the DGEBA resin and no agglomerate was observed (Figure 3) [18].

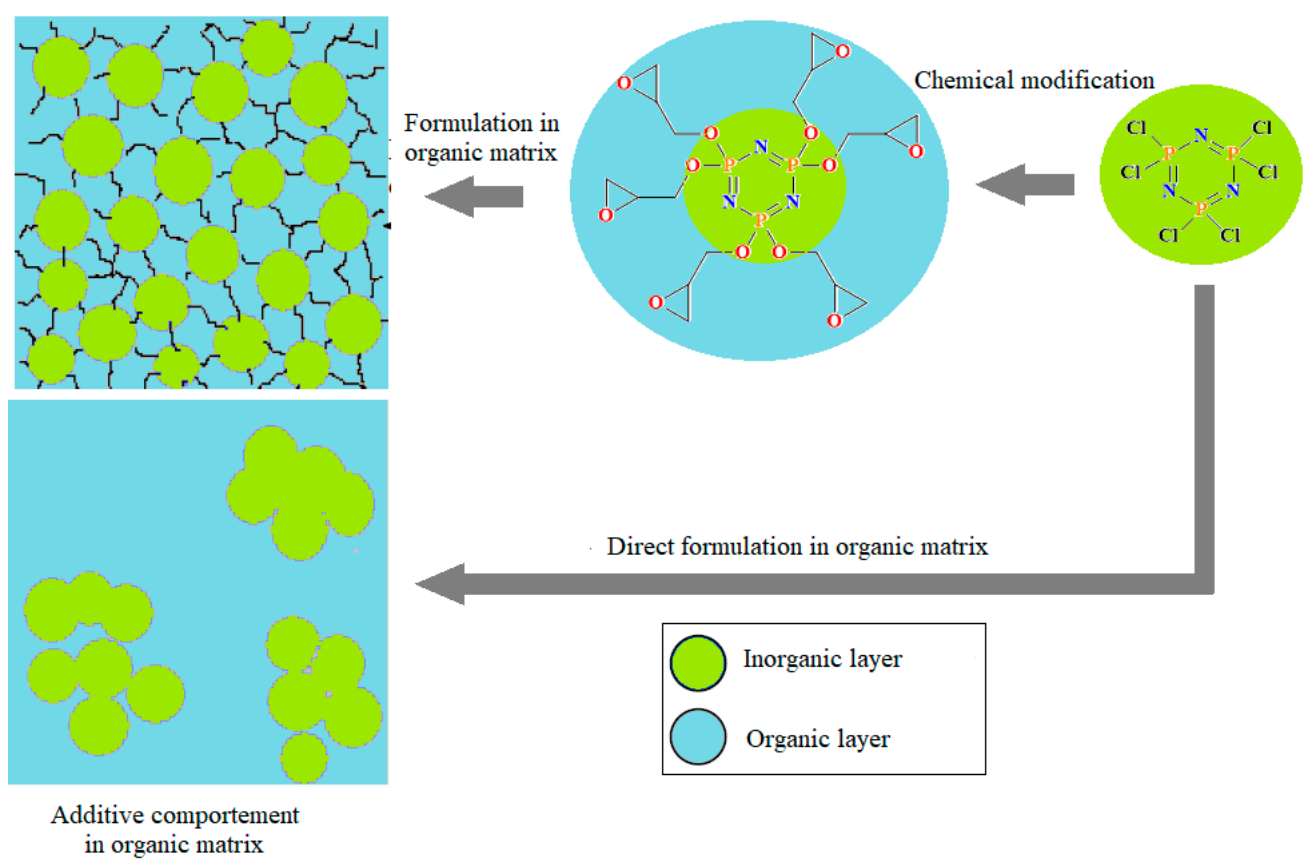

Figure 3. Dispersed hexaglycidyl of cyclotriphosphazene (HGCP) in an organic matrix diglycidyl ether of bisphenol A (DGEBA). 
Compared to the composite ([NPCl 2$]_{3}$-DGEBA), the aggregations were observed in the latter composite. This suggests that the modified chlorocyclophosphazene may be well dispersed in DGEBA, which resulted from improved compatibility with DGEBA resin and the crosslinked structure of cyclophosphazene. In this work, while HGCP had good dispersion in DGEBA epoxy resin, the study will focus on the effect of HGCP in the physical behavior of materials based on DGEBA epoxy resin.

\subsection{Morphological Characterization}

The observations morphological were carried out on a scanning electron microscope (SEM) of the JEOL-JSM-5500 type (Dearborn, MI, US), whose maximum resolution is $3.5 \mathrm{~nm}$ with a magnification ranging from 18 to 300,000 times and automatic focus adjustment (contrast, brightness, stigmatism), the acceleration voltage varies from 0.5 to $30 \mathrm{KV}$. A computer control system allowed images to be digitized using image processing software (JEOL, Dearborn, MI, US).

\subsection{Rheological Measurement}

For the measurement of rheological properties, an imposed constraint Rheometer of the HAAKE MARS Modular Advanced Rheometer System type (Thermo-Scientific, Karlsruhe, Germany) was used. This instrument is equipped with different measuring bodies. Our study is carried out with a plane-plane geometry with a diameter of $25 \mathrm{~mm}$ and a thickness of $1.8 \mathrm{~mm}$. The dynamic oscillatory measurements were made using a frequency sweep ranging from 0.1 to $100 \mathrm{rad} / \mathrm{s}$ with a constant applied strain of $0.1 \%$ which is in the linear viscoelastic region. All measurements were taken at a constant temperature of $100^{\circ} \mathrm{C}$.

\subsection{Electrical Measurements}

The electrical measurements were carried out at room temperature on samples. The impedance measurements (capacitance-frequency) were carried out using a Keithley 3330LCZ impedance meter (Oceanside, CA, US). All instruments are controlled by a computer via a GPIB card.

\section{Results and Discussions}

\subsection{Morphology Study}

The SEM micrograph of DGEBA sample mixed with HGCP is shown in Figure 4. For all quantities of $10 \%$ HGCP, the sample was uniform and examination of their surface morphology revealed no pinholes or porosity.

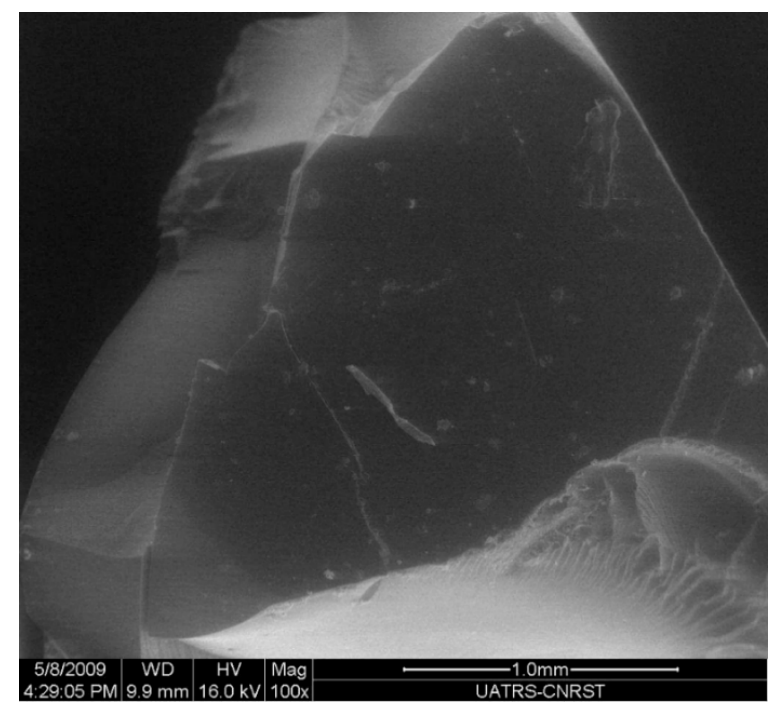

Figure 4. SEM micrograph of the DGEBA samples mixed with HGCP. 


\subsection{Dynamic Viscoelastic Analyzes}

Work on the rheological behavior of composites, i.e., macroscopic dynamic viscoelastic behavior, has often made it possible to better understand the structures and relationships responsible for the reinforcement of polymers by HGCP particles. Rheology therefore places itself here on the border between structural determination and physical properties of composites; moreover, this technique is often the key in understanding and improving the implementation. The elastic modulus G' (solid symbols) and the loss modulus G "(open symbols) of the DGEBA / HGCP / MDA composites were measured in the linear range at $100{ }^{\circ} \mathrm{C}$ and in a frequency range from $0.1-100 \mathrm{rad} / \mathrm{s}$, the results are given in the Figure 5.

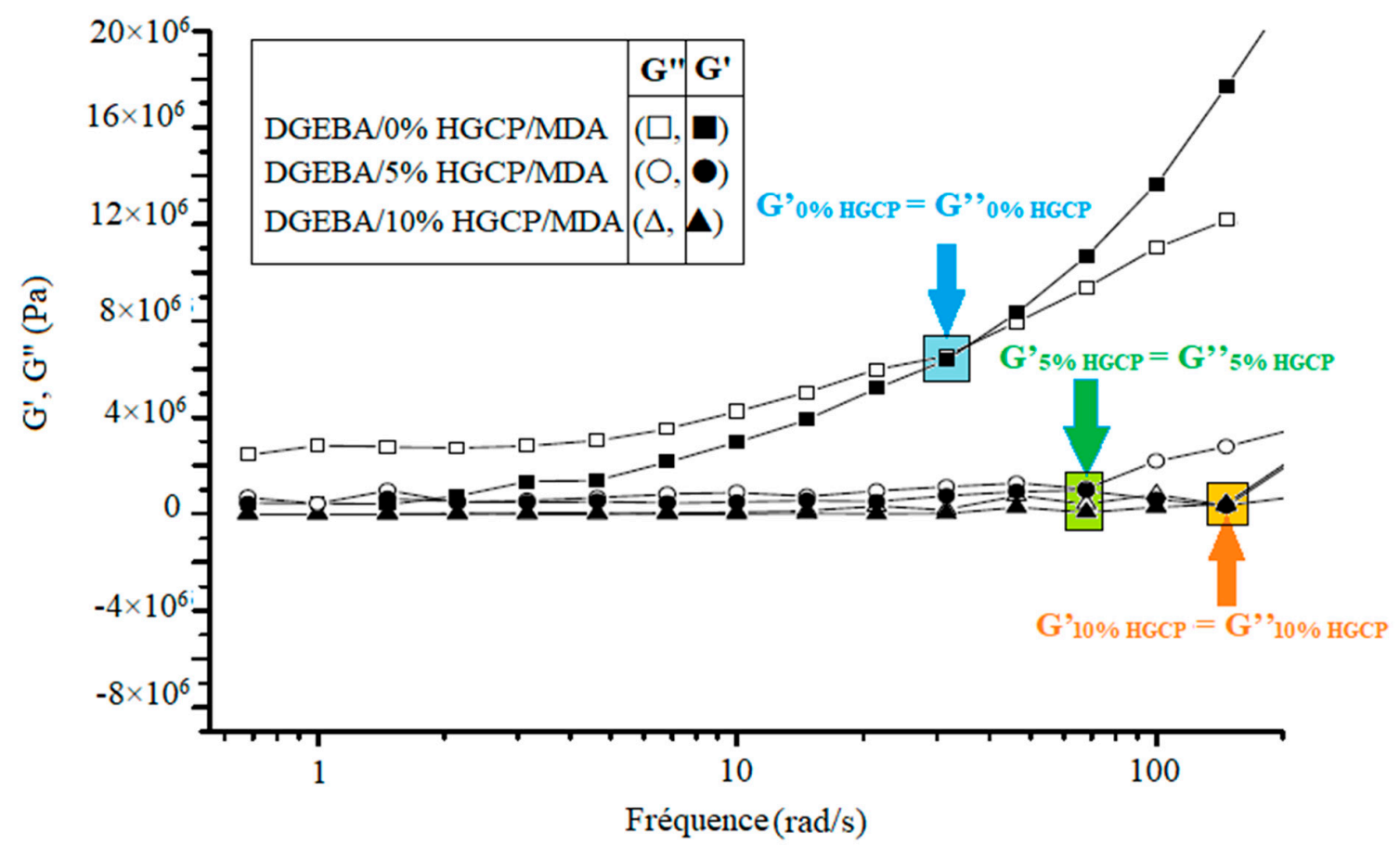

Figure 5. Modulus of elasticity $G^{\prime}$ and modulus of loss $G^{\prime \prime}$ as a function of the frequency of the composites.

These measurements were obtained by applying a constant deformation of $0.1 \%$, which is in the linear viscoelastic region. The results show that all the $0 \%, 5 \%$ and $10 \%$ mixtures of HGCP dispersion behaved like a solid, with $G$ 'and $G$ "almost independent of frequency and G'> G". The value of $G^{\prime}$ and $G$ "decreased with increasing amount of HGCP in the epoxy resin DGEBA. At high frequency, we can observe the crossover frequency when $G^{\prime}=G^{\prime \prime}$. The latter increased with the increase in the quantity of HGCP, which reflects the elastic behavior of the samples. These effects were also observed on other polymers [19]. These composites would be caused by long distance density fluctuations, kinetically frozen at measurement frequencies due to their extremely long relaxation [20]. Furthermore, the increase in the storage module and the loss module for different composites is a common phenomenon for the crosslinked and reinforced epoxy resin, which can be explained by the interaction between the resin and the HGCP hindering the movement of the macromolecular chains [21,22].

Figure 6 shows the conservation of the module $G^{\prime}$ as a function of the deformation for the DGEBA samples with different quantities of $\operatorname{HGCP}(0 \%, 5 \%$ and $10 \%)$. 


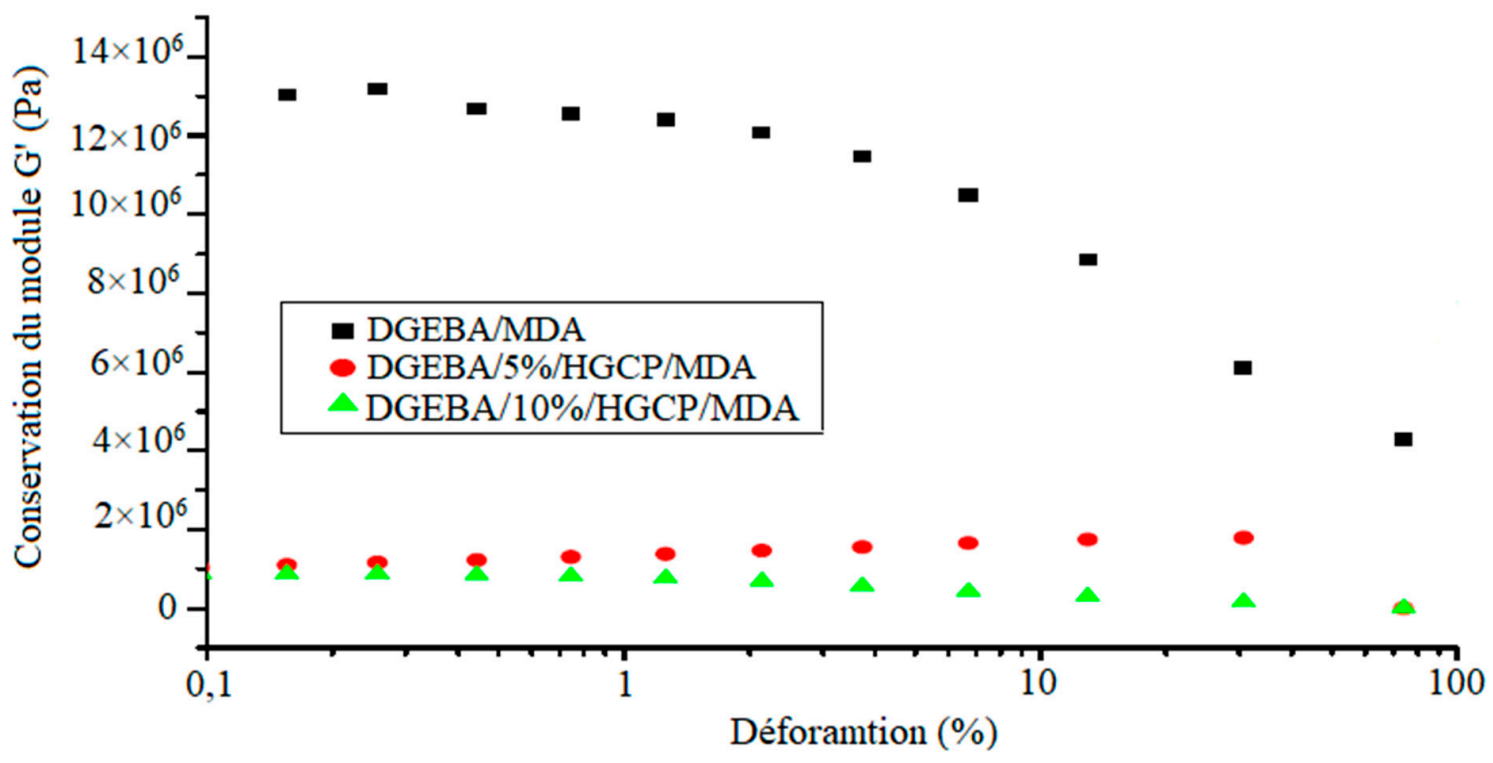

Figure 6. Conservation of the module $\mathrm{G}^{\prime}$ as a function of the deformation for the DGEBA/HGCP/ MDA samples.

In all cases, an increase in the linear field was observed when the amount of HGCP increased. For these systems where the HGCP was well dispersed in the DGEBA, the curves did not show any particular characteristic compared to the linear field for a pure DGEBA.

The stress-strain curves for the DGEBA samples with different quantities of HGCP $(0 \%, 5 \%$ and $10 \%$ ) are illustrated in the Figure 7.

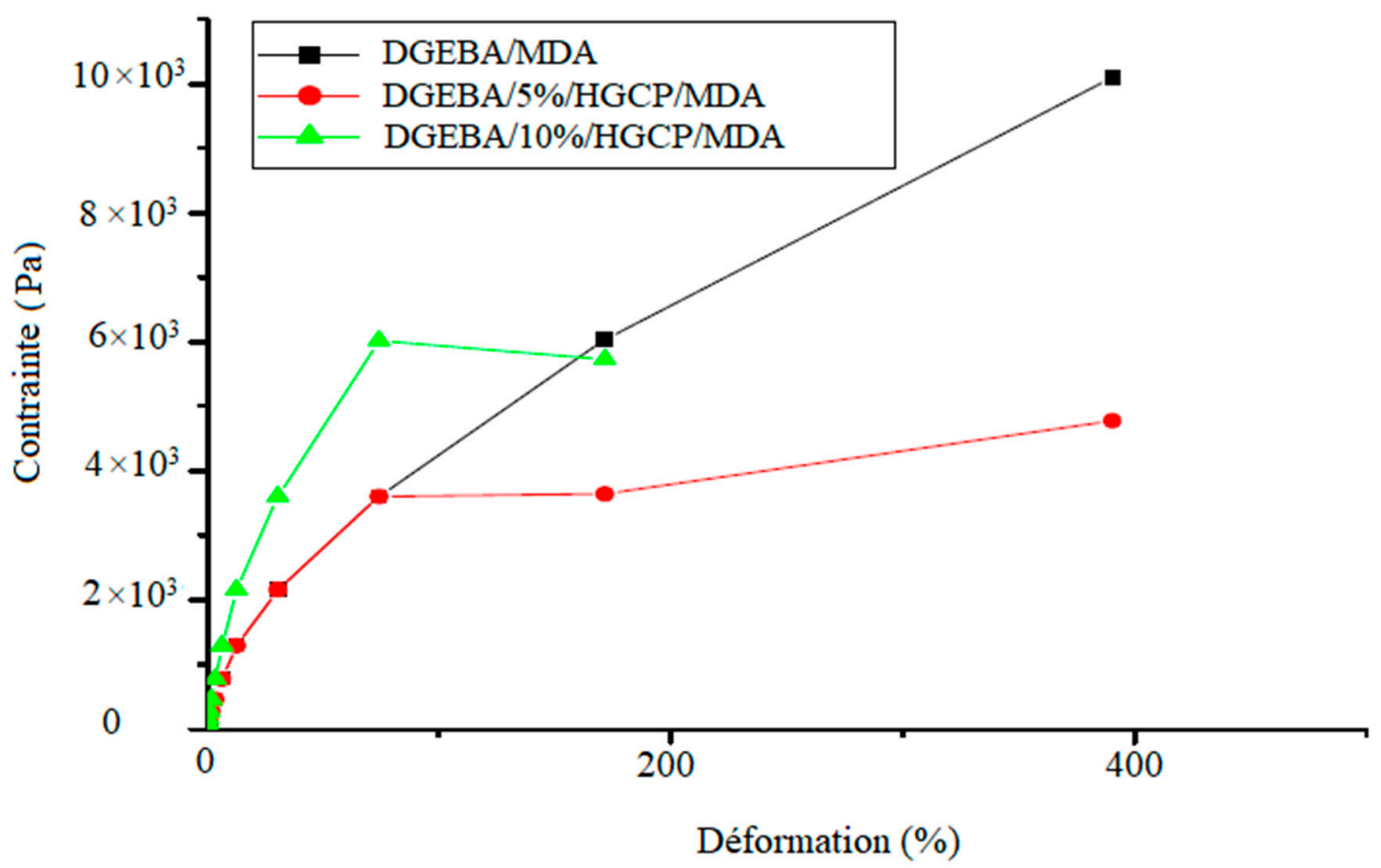

Figure 7. Stress-strain curves for DGEBA samples with different amounts of $\mathrm{HGCP}(0 \%, 5 \%$ and $10 \%)$.

The mechanical properties of the DGEBA material modified by the addition of HGCP exhibited better ductility compared to pure DGEBA-MDA and also he observed that the breaking strain of the DGEBA-HGCCP-MDA material was significantly higher than that of the DGEBA resin pure. The presence of HGCP in the DGEBA resin results in the appearance of a plastic deformation zone from $74.33 \%$ deformation. However, the tensile strength decreased after the introduction of $10 \%$ HGCP 
into the DGEBA resin and the modulus of elasticity by a factor of 2 which can be attributed to the increase in knots in the matrix. In other cases, the result indicates that the introduction of HGCP into the DGEBA resin makes the samples more flexible. This increased flexibility of the samples can be attributed to the free volume presented by the HGCP / MDA / DGEBA network, promote molecular movement and improve the tensile strength [23].

\subsection{Electric Properties}

Figure 8 shows the capacity-frequency characteristics of (DGEBA/HGCP/MDA) in the frequency range $1-100 \mathrm{kHz}$. The capacity decreased by a factor of two when the frequency was increased to $100 \mathrm{kHz}$. This dispersion of capacity can be explained by the distribution of the localized states in the band gaps of HGCP network [24], barrier inhomogeneities and series resistance. At high frequency $(1 \mathrm{kHz})$, the deep states could not follow the barrier modulation and the capacitance must be replaced by the dielectric capacitance of the matrix. In addition, for $5 \%$ and $10 \%$ of the quantity of HGCP, the capacity of the samples increased. This could be due to the increase in nods in the samples.

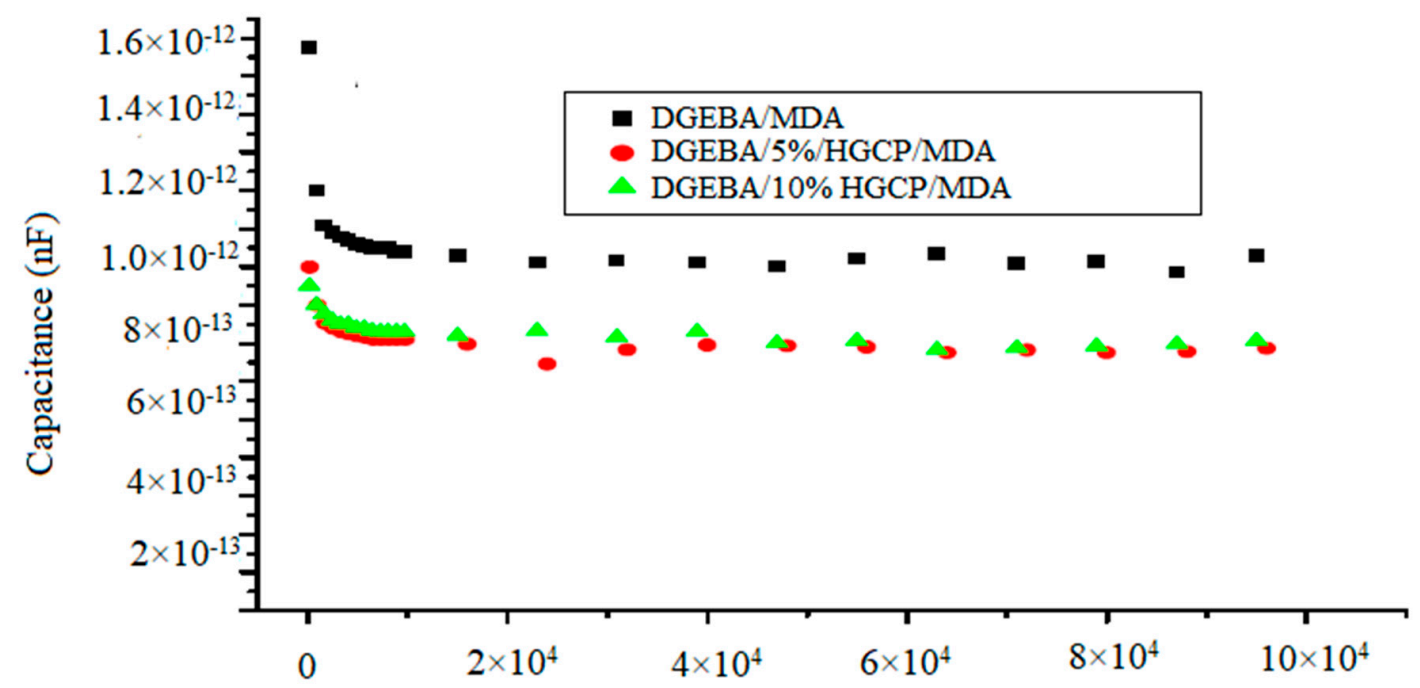

Figure 8. Capacity-frequency characteristics for DGEBA samples with different quantities of HGCP $(0 \%, 5 \%$ and $10 \%)$.

\section{Conclusions}

Various composite materials based on the epoxy resin DGEBA, MDA as hardener and the epoxy resin HGCP as an additive were prepared and formulated. The presence of a small amount $(5 \%$ and $10 \%$ by weight) of HGCP showed high improvement in the mechanical and electrical properties of the DGEBA based epoxy materials. The chemical modification of cyclophosphazene facilitated better dispersion by optimizing the compatibility between the organic matrix and the cyclophosphazene. The presence of HGCP in the DGEBA resin showed a significant improvement in flexural modulus and hardness, which could be attributed to the flexibility of HGCP within a matrix stretched via the free volume present in the DGEBA network and also appearance of a plastic deformation zone from $74.33 \%$ deformation. However, the tensile strength decreased after the introduction of $10 \%$ HGCP into the DGEBA resin and the modulus of elasticity by a factor of 2 . In addition, for $5 \%$ and $10 \%$ of the quantity of HGCP in the DGEBA, the capacity of the samples increases. This could be due to the increase in nods in the samples.

Author Contributions: O.D., A.E.B., M.E.G., B.K., A.E.M. and A.O. conceived and designed the experiments. O.D. and G.H. conducted the experiments. O.C., A.E.H., S.J. and O.H. wrote the paper. All authors have read and agreed to the published version of the manuscript.

Funding: Part of financial support comes from PADUCO-2 for small grant research. And from An-Najah National University Research Science. 
Acknowledgments: We acknowledge both An-Najah National University and University of Ibn Tofail for helping us using their laboratories.

Conflicts of Interest: The author declares no conflict of interest

\section{References}

1. Saeb, M.R.; Rastin, H.; Nonahal, M.; Paran, S.M.R.; Khonakdar, H.A.; Puglia, D. Cure kinetics of epoxy/chicken eggshell biowaste composites: Isothermal calorimetric and chemorheological analyses. Prog. Org. Coat. 2018, 114, 208-215. [CrossRef]

2. Puglia, D.; Rastin, H.; Saeb, M.R.; Shojaei, B.; Formela, K. Cure kinetics of epoxy/MWCNTs nanocomposites: Isothermal calorimetric and rheological analyses. Prog. Org. Coat. 2017, 108, 75-83.

3. Duan, H.; Chen, Y.; Ji, S.; Hu, R.; Ma, H. A novel phosphorus/nitrogen-containing polycarboxylic acid endowing epoxy resin with excellent flame retardance and mechanical properties. Chem. Eng. J. 2019, 375, 121916. [CrossRef]

4. Guo, X.; Wang, H.; Ma, D.; He, J.; Lei, Z. Synthesis of a novel, multifunctional inorganic curing agent and its effect on the flame-retardant and mechanical properties of intrinsically flame retardant epoxy resin. J. Appl. Polym. Sci. 2018, 135, 46410. [CrossRef]

5. Zheng, T.; Wang, X.; Lu, C.; Zhang, X.; Ji, Y.; Bai, C.; Qiao, Y. Studies on curing kinetics and tensile properties of silica-filled phenolic amine/epoxy resin nanocomposite. Polymers 2019, 11, 680. [CrossRef]

6. Rudawska, A. The impact of the seasoning conditions on mechanical properties of modified and unmodified epoxy adhesive compounds. Polymers 2019, 11, 804. [CrossRef]

7. Wang, T.; Song, B.; Wang, L. A New filler for epoxy resin: Study on the properties of graphite carbon nitride (g-C3N4) reinforced epoxy resin composites. Polymers 2020, 12, 76. [CrossRef]

8. Bao, Q.; Wang, B.; Liu, Y.; Wang, Q.; Yang, Z. Epoxy resin flame retarded and toughed via flexible siloxane chain containing phosphaphenanthrene. Polym. Degrad. Stab. 2020, 172, 109055. [CrossRef]

9. Chistyakov, E.M.; Panfilova, D.V.; Kireev, V.V.; Volkov, V.V.; Bobrov, M.F. Synthesis and properties of hexakis-( $\beta$-carboxyethenylphenoxy) cyclotriphosphazene. J. Mol. Struct. 2017, 1148, 1-6. [CrossRef]

10. Zhou, L.; Zhang, G.; Yang, S.; Yang, L.; Cao, J.; Yang, K. The synthesis, curing kinetics, thermal properties and flame rertardancy of cyclotriphosphazene-containing multifunctional epoxy resin. Thermochim. Acta 2019, 680, 178348. [CrossRef]

11. Cheng, J.; Wang, J.; Yang, S.; Zhang, Q.; Hu, Y.; Ding, G.; Huo, S. Aminobenzothiazole-substituted cyclotriphosphazene derivative as reactive flame retardant for epoxy resin. React. Funct. Polym. 2020, 146, 104412. [CrossRef]

12. Cheng, J.; Wang, J.; Yang, S.; Zhang, Q.; Huo, S.; Zhang, Q.; Ding, G. Benzimidazolyl-substituted cyclotriphosphazene derivative as latent flame-retardant curing agent for one-component epoxy resin system with excellent comprehensive performance. Compos. Part B Eng. 2019, 177, 107440. [CrossRef]

13. Dagdag, O.; El Harfi, A.; El Gouri, M.; Safi, Z.; Jalgham, R.T.; Wazzan, N.; Kumar, U.P. Anticorrosive properties of Hexa (3-methoxy propan-1, 2-diol) cyclotri-phosphazene compound for carbon steel in 3\% $\mathrm{NaCl}$ medium: Gravimetric, electrochemical, DFT and Monte Carlo simulation studies. Heliyon 2019, 5, e01340. [CrossRef] [PubMed]

14. Shariati, A.; Peters, C.J. Recent developments in particle design using supercritical fluids. Curr. Opin. Solid State Materi. Sci. 2003, 7, 371-383. [CrossRef]

15. Quede, A.; Mutel, B.; Supiot, P.; Jama, C.; Dessaux, O.; Delobel, R. Characterization of organosilicon films synthesized by N2-PACVD. Application to fire retardant properties of coated polymers. Surf. Coat. Technol. 2004, 180, 265-270. [CrossRef]

16. El Gouri, M.; El Bachiri, A.; Hegazi, S.E.; Rafik, M.; El Harfi, A. Thermal degradation of a reactive flame retardant based on cyclotriphosphazene and its blend with DGEBA epoxy resin. Polym. Degrad. Stab. 2009, 94, 2101-2106. [CrossRef]

17. Levan, Q. Thèse de Docteur-Ingénieur; INP Toulouse: Toulouse, France, 1981.

18. El Gouri, M.; El Bachiri, A.; Hegazi, S.E.; Ziraoui, R.; Rafik, M.; El Harfi, A. A phosphazene compound multipurpose application-Composite material precursor and reactive flame retardant for epoxy resin materials. J. Mater. Environ. Sci. 2011, 2, 319-334. 
19. Lertwimolnun, W.; Vergnes, B. Influence of compatibilizer and processing conditions on the dispersion of nanoclay in a polypropylene matrix. Polymer 2005, 46, 3462-3471. [CrossRef]

20. Cassagnau, P.; Melis, F. Non-linear viscoelastic behaviour and modulus recovery in silica filled polymers. Polymer 2003, 44, 6607-6615. [CrossRef]

21. Treece, M.A.; Oberhauser, J.P. Soft glassy dynamics in polypropylene-clay nanocomposites. Macromolecules 2007, 40, 571-582. [CrossRef]

22. Aoki, Y.; Hatano, A.; Watanabe, H. Rheology of carbon black suspensions. I. Three types of viscoelastic behavior. Rheol. Acta 2003, 42, 209-216. [CrossRef]

23. Li, J.; Wang, H.; Li, S. A novel phosphorus- silicon containing epoxy resin with enhanced thermal stability, flame retardancy and mechanical properties. Polym. Degrad. Stab. 2019, 164, 36-45. [CrossRef]

24. Misra, S.C.K.; Chandra, S. Electronic applications of semiconducting polymers. Indian J. Chem. 1994, 33A, 583-594.

(C) 2020 by the authors. Licensee MDPI, Basel, Switzerland. This article is an open access article distributed under the terms and conditions of the Creative Commons Attribution (CC BY) license (http://creativecommons.org/licenses/by/4.0/). 